\title{
Association between increased epicardial adipose tissue volume and coronary plaque composition
}

\author{
Kennosuke Yamashita $\cdot$ Myong Hwa Yamamoto $\cdot$ Seitarou Ebara $\cdot$ \\ Toshitaka Okabe $\cdot$ Shigeo Saito $\cdot$ Koichi Hoshimoto - Tadayuki Yakushiji • \\ Naoei Isomura $\cdot$ Hiroshi Araki $\cdot$ Chiaki Obara $\cdot$ Masahiko Ochiai
}

Received: 9 April 2013/Accepted: 2 August 2013/Published online: 28 August 2013

(C) The Author(s) 2013. This article is published with open access at Springerlink.com

\begin{abstract}
To assess the relationship between epicardial adipose tissue volume (EATV) and plaque vulnerability in significant coronary stenosis using a $40-\mathrm{MHz}$ intravascular ultrasound (IVUS) imaging system (iMap-IVUS), we analyzed 130 consecutive patients with coronary stenosis who underwent dual-source computed tomography (CT) and cardiac catheterization. Culprit lesions were imaged by iMap-IVUS before stenting. The iMAP-IVUS system classified coronary plaque components as fibrous, lipid, necrotic, or calcified tissue, based on the radiofrequency spectrum. Epicardial adipose tissue was measured as the tissue ranging from -190 to -30 Hounsfield units. EATV, calculated as the sum of the fat areas on short-axis images, was $85.0 \pm 34.0 \mathrm{~cm}^{3}$. There was a positive correlation between EATV and the percentage of necrotic plaque tissue $\left(R^{2}=0.34, P<0.01\right)$, while there was a negative correlation between EATV and the percentage of fibrous tissue $\left(R^{2}=0.24, P<0.01\right)$. Multivariate analysis revealed that an increased low-density lipoprotein cholesterol level ( $\beta=0.15, P=0.03)$ and EATV $(\beta=0.14, P=0.02)$ were independently associated with the percentage of necrotic plaque tissue. An increase in EATV was associated with the development of coronary atherosclerosis and, potentially, with the most dangerous type of plaque.
\end{abstract}

Keywords Adipose tissue - Coronary artery disease . Percutaneous coronary intervention

K. Yamashita $(\bowtie) \cdot$ M. H. Yamamoto · S. Ebara · T. Okabe

S. Saito · K. Hoshimoto · T. Yakushiji · N. Isomura ·

H. Araki - C. Obara - M. Ochiai

Division of Cardiology and Cardiac Catheterization

Laboratories, Showa University Northern Yokohama Hospital,

35-1, Chigasaki-chuo, Tsuzuki, Yokohama,

Kanagawa 224-8503, Japan

e-mail: kennosuke.atmm3@gmail.com

\section{Introduction}

Epicardial adipose tissue (EAT) and intra-abdominal visceral fat share a common embryological origin, the splanchnopleuric mesoderm [1]. The pericardial adipose tissue derives its blood supply from noncoronary vessels such as the pericardiacophrenic branches of the internal mammary artery, while EAT is supplied by the coronary arteries. It was reported that the EAT volume is larger in the presence of vulnerable plaques, independently of indices of obesity (body mass index (BMI) and visceral adipose tissue) and the coronary artery calcification (CAC) score [2-7]. In addition, vulnerable plaque is related to coronary events [8], and methods of detecting vulnerable plaques have not been established. The iMAP system (Boston Scientific, Natick, MA, USA) is useful for the assessment of plaque composition by using spectral analysis of intravascular ultrasound (IVUS) radiofrequency data [9]. Accordingly, we investigated the relationship between epicardial adipose tissue volume (EATV) and plaque vulnerability in patients with significant coronary stenosis using a 40-MHz IVUS imaging system [10].

\section{Patients and methods}

Patients and study design

Data were reviewed for 249 consecutive patients with de novo coronary artery lesions who underwent elective percutaneous coronary intervention (PCI) at our institution during the period from September 2011 to June 2012. We selected the most stenotic lesion per subject, and IVUS was performed for vessels with $>50 \%$ diameter stenosis on quantitative coronary angiography (QCA). A total of 119 patients were excluded because of in-stent restenosis 
$(n=38)$, a history of coronary artery bypass graft surgery $(n=1)$, chronic total occlusion $(n=15)$, severe calcification that the IVUS catheter could not cross $(n=36)$, or no multislice computed tomography (CT) within 3 months $(n=29)$ (Fig. 1). As a result, the present study assessed 130 consecutive patients with stenosis who underwent de novo coronary intervention. The smoking status, medical history, and current cardiovascular medications (for hypertension, dyslipidemia, and diabetes) were assessed by a questionnaire. Height (meters) and weight (kilograms) were measured before coronary angiography to calculate the body mass index, and systolic and diastolic blood pressures were measured while the patient was in the supine position before $\mathrm{CT}$ was performed.

PCI strategy and antiplatelet therapy

PCI was performed according to standard methods via the radial or femoral approach using a 6-F or larger guide catheter to facilitate subsequent QCA. Treatment with oral aspirin was started prior to the procedure. Following sheath insertion, unfractionated heparin was administered as bolus doses of 150 units $/ \mathrm{kg}$ during the procedure to maintain an activated clotting time (ACT) from 250 to $300 \mathrm{~s}$. The ACT was measured both before and during PCI. PCI was performed if patients had no contraindications, such as intolerance to aspirin or ticlopidine and scheduled noncardiac surgery (among others). Additional antiplatelet therapy with either clopidogrel $(75 \mathrm{mg} /$ day after a loading dose of $300 \mathrm{mg}$ ) or ticlopidine ( $200 \mathrm{mg} /$ day) was started in all patients after PCI and was continued for at least 1 year.

Angiographic analyses

The minimum luminal diameter (MLD), reference diameter, and pre- and postprocedural percent diameter stenosis

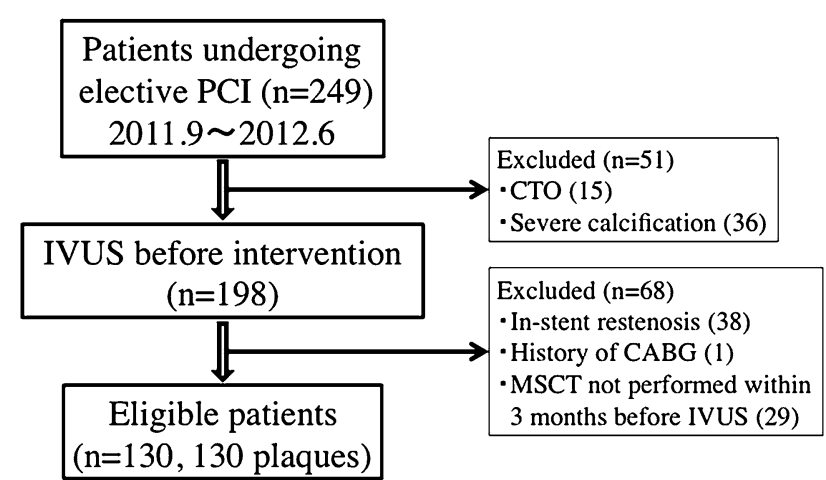

Fig. 1 Disposition of the patients. PCI percutaneous coronary intervention, IVUS intravascular ultrasound, CTO chronic total occlusion, $C A B G$ coronary artery bypass grafting, MSCT multislicerow computed tomography of the lesion were determined with an automated edge detection system (CASSII; PieMedical, Maastricht, The Netherlands). Images were analyzed by a radiologist [11] who was not involved in the study to avoid bias. The contrast-filled catheter tip was used as the calibration standard. All measurements were performed on cine angiograms recorded after intracoronary administration of nitroglycerin. QCA measurements were obtained on both an in-stent basis (confined to the stented region) and in-segment basis (including the vessel $5 \mathrm{~mm}$ proximal and distal to the stent). Acute gain was defined as the difference between the postprocedural and preprocedural MLD, while late loss was defined as the difference between the postprocedural MLD and that obtained at follow-up. The reference diameter was defined as the average of the proximal and distal reference diameters of the target vessel before repeat PCI.

Intravascular ultrasound examination and analysis

IVUS was performed in all patients before PCI. In brief, after administration of intracoronary nitroglycerin $(125-250 \mu \mathrm{g})$, a 3.6-F 40-MHz IVUS catheter (Atlantis SR Pro; Boston Scientific) was introduced into the distal coronary artery. This catheter was then withdrawn by an automatic pullback system at a rate of $0.5 \mathrm{~mm} / \mathrm{s}$ until the coronary ostium was observed. Quantitative volumetric analysis of the IVUS data was performed according to the American College of Cardiology Clinical Expert Consensus Document on Standards for Acquisition, Measurement, and Reporting of IVUS [12]. The vessel and lumen were manually traced at $0.5-\mathrm{mm}$ intervals. Then the luminal volume, vessel volume, and plaque volume (vessel liminal volume) were computed using Simpson's method. Plaque burden was calculated as follows: (cross-sectional area of the plaque/cross-sectional area of the vessel) $\times 100$. The minimum luminal cross-sectional area (MLA) was defined as the smallest luminal cross-sectional area inside the lesion. Reference vessel cross-sectional area was defined as the mean of the proximal and distal cross-sectional areas of the reference vessel. The percent stenosis was calculated as (MLA/reference vessel cross-sectional area) $\times 100$, while the remodeling index (RI) was calculated as vessel cross-sectional area at the MLA site/reference vessel cross-sectional area. A 10-mm segment of the culprit lesion (from $5 \mathrm{~mm}$ proximal to $5 \mathrm{~mm}$ distal to the culprit site) was selected [13] for analysis by iMap-IVUS. In brief, the iMAP system performed spectral analysis of IVUS radiofrequency data. The borders of the vessel and lumen were identified by automatic edge detection and corrected manually when necessary (Fig. 2). Subsequently the iMAP system automatically classified the plaque into four major components, which were fibrous tissue (labeled green), lipid tissue (labeled yellow), necrotic tissue 
Fig. 2 The technique of intravascular ultrasound (IVUS) and iMap classifies the plaque tissue into four color-coded components: green (fibrous), yellow (lipid), pink (necrotic), and blue (calcified). The software used for analysis allows exclusion of the wire shadow from tissue characterization as unknown plaque (black) and/or exclusion of the tissue behind calcification

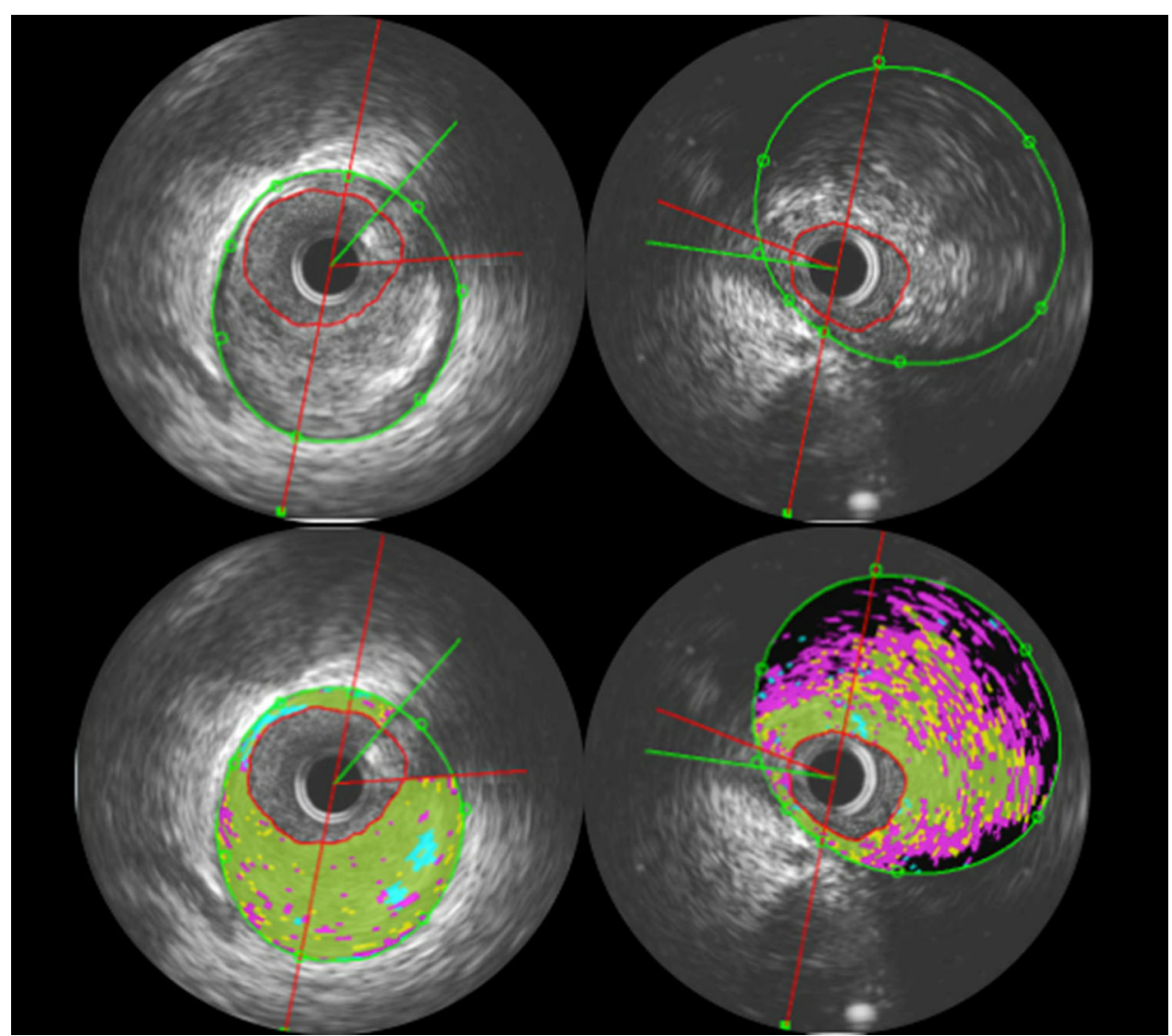

(labeled pink), and calcified tissue (labeled blue), according to a previously reported algorithm [10]. Plaque that was unsuitable for analysis was defined as that affected by acoustic shadowing behind calcification or wire artifacts, and was automatically deleted because it could not be analyzed accurately. The anatomic distribution of plaque in proximal, mid, and distal coronary segments of the left anterior descending artery, left circumflex coronary artery, right coronary artery, and left main artery was also determined.

\section{CT protocol}

A dual-source CT system (Somatom Definition; Siemens Medical Solutions, Forchheim, Germany) was used with the following settings: detector collimation $64 \times 0.625$ $\mathrm{mm}$, table feed $19.7 \mathrm{~mm} / \mathrm{s}, 0.17$ helical pitch (beam pitch), rotation time $280 \mathrm{~ms}$, tube current $370 \mathrm{~mA} \mathrm{~s}$, and voltage $120 \mathrm{kVp}$. The scanning time varied from 6 to $8 \mathrm{~s}$. Raw scan data were reconstructed with $75 \%$ of RR wave or the particular optimal phase. A bolus dose of the contrast medium iohexol (Omnipaque; Daiichi-Sankyo Pharmaceutical, Tokyo, Japan) containing $350 \mathrm{mg}$ iodine/ml was injected at $0.6 \mathrm{ml} / \mathrm{kg}$ within $9 \mathrm{~s}$. In all patients, a $\beta$-blocker (bisoprolol fumarate, $2.5 \mathrm{mg}$ ) was administered orally $1 \mathrm{~h}$ prior to CT scanning, and nitroglycerin $(0.3 \mathrm{mg})$ was given just before scanning. The reconstructed CT scans were transferred to a workstation for postprocessing (Ziostation; Amin, Tokyo, Japan). CAC was quantified by the Agatston score [14].

\section{Measurement of EATV}

EAT was defined as any adipose tissue located within the pericardial sac. It was identified on contrast-enhanced CT scans as a hypodense rim surrounding the myocardium and limited by the pericardium. Axial slices $(0.75 \mathrm{~mm}$ thick) of the heart were obtained from the level of the right pulmonary artery to the diaphragm and a predefined image display setting was used (window width of 80 Hounsfield units (HU) and window center of $-110 \mathrm{HU}$ ) to identify pixels that corresponded to adipose tissue [15]. Readers who were blind to the clinical data then trimmed along the pericardial sac on axial, coronal, and sagittal slices, as well as volume-rendered images (Fig. 3).

Statistical methods

Data were analyzed with JMP software (SAS Institute, Cary, NC, USA) using analysis of variance (ANOVA). 
Fig. 3 a The epicardial adipose tissue area (red) was determined by tracing a single region of interest (blue) on an axial image. Fat voxels were identified by using a threshold attenuation range of -190 to $-30 \mathrm{HU}$. b Epicardial adipose tissue volume $(E A T V)\left(\mathrm{cm}^{3}\right)$ was automatically calculated as the sum of the fat areas at least $1.0 \mathrm{~mm}$ thick for the whole heart
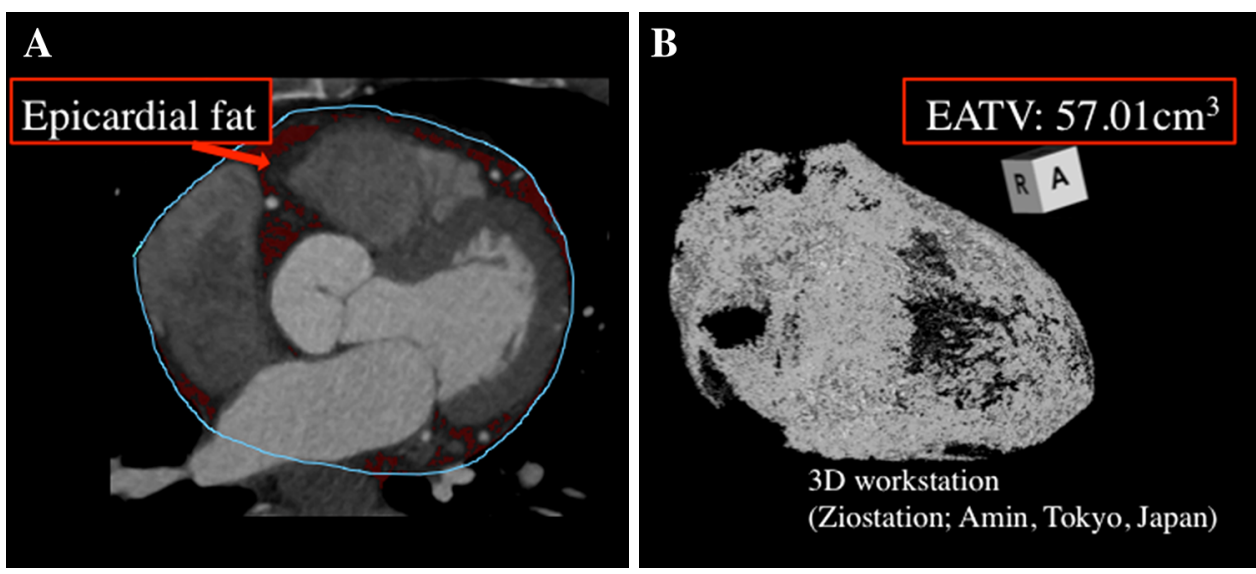

Categorical data are expressed as frequencies and were compared with Pearson's Chi-square test. Continuous variables are presented as the mean \pm standard deviation and were compared using Student's $t$ test or ANOVA. Comparison between coronary plaque tissue composition and EATV was done with univariate linear regression analysis, after which multivariate analysis was performed based on the results of the univariate analysis. In all analyses, a probability $(P)$ value of less than 0.05 was considered statistically significant.

\section{Ethical considerations}

Written informed consent was obtained from all subjects, and the ethical committee of our institution approved the study protocol.

\section{Results}

The mean EATV of all patients was $85.0 \mathrm{~cm}^{3}$ (range $16.7-186.4 \mathrm{~cm}^{3}$ ). Based on this mean value, patients were divided into a low-EATV group (EATV $<85.0 \mathrm{~cm}^{3}, n=65$ ) and a high-EATV group (EATV $\geq 85.0 \mathrm{~cm}^{3}, n=65$ ).

High- and low-EATV groups

With regard to clinical characteristics, there were no significant differences between the two groups in terms of the age, sex, BMI, and prevalence of diabetes (Table 1). Regarding medications, the percentage of patients using statins was significantly larger in the high-EATV group, accounting for $61.5 \%$ of the high-EATV group versus 38.5 $\%$ of the low-EATV group. As shown in Table 2, there were no significant differences between the two groups in terms of angiographic characteristics such as the severity of stenosis, lesion length, and lesion distribution. IVUS data are shown in Table 3. No difference was detected between the two groups with respect to the MLA and lumen volume at the lesions. The reference area at the MLA site was larger in the high-EATV group than in the low-EATV group (76.5 \pm 8.3 vs $72.9 \pm 10.2, P=0.03)$, but there was no significant difference in the remodeling index. Also, positive remodeling was more advanced in the high-EATV group $(1.08 \pm 0.16$ vs $0.87 \pm 0.14, P=0.04)$. Plaque volume at the lesion was larger in the high-EATV group than in the low-EATV group. Furthermore, additional analysis of plaque characteristics revealed significantly higher percentages of lipid, necrotic, and calcified tissues in plaque from the high-EATV group. With regard to fibrous tissue, however, no significant difference was detected between the two groups. Subsequently, we assessed the correlation between EATV and MLA (Fig. 4), the vessel diameter at the MLA site, the plaque volume at the lesion site, and the blood vessel volume, but no significant correlations were found among these factors. We also assessed the correlation between EATV and each plaque component (Fig. 5), revealing a significant negative correlation between EATV and fibrous tissue $\left(R^{2}=0.24\right.$, $P<0.01$ ), as well as a significant positive correlation between EATV and necrotic tissue $\left(R^{2}=0.34, P<0.01\right)$. However, lipid tissue and calcified tissue showed no significant correlation with EATV. We also performed multivariate analysis of the variables related to necrotic plaque, which is regarded as vulnerable plaque, employing hemoglobin $\mathrm{A}_{1 \mathrm{c}}\left(\mathrm{HbA}_{1 \mathrm{c}}\right)$, low-density lipoprotein (LDL) cholesterol, high-density lipoprotein (HDL) cholesterol, eicosapentaenoic acid/arachidonic acid (EPA/AA) ratio, highly sensitive C-reactive protein, $\mathrm{BMI}$, and smoking status. As a result, LDL cholesterol $(\beta=0.15, P=0.03)$ and EATV ( $\beta=0.14, P=0.02)$ were identified as factors predicting plaque with a high percentage of necrotic tissue (Table 4). In addition, we performed multivariate analysis of the variables related to necrotic tissue in high-EATV group. LDL cholesterol ( $\beta=0.10, P=0.04)$ was identified as a factor. However, correlation was very weak. 
Table 1 Comparison of clinical characteristics

\author{
$A A$ arachidonic acid, Apo \\ apolipoprotein, $A R B$ angiotensin \\ receptor blocker, $B M I$ body \\ mass index, $C A C$ coronary \\ artery calcification, $C C B$ \\ calcium-channel blocker, \\ $\mathrm{Cr}$ creatinine, EPA \\ eicosapentaenoic acid, $H b A_{l c}$ \\ hemoglobin $\mathrm{A}_{1 \mathrm{c}}, H D L$ high- \\ density lipoprotein, $h s-C R P$ \\ highly sensitive C-reactive \\ protein, $L D L$ low-density \\ lipoprotein
}

\begin{tabular}{|c|c|c|c|}
\hline Clinical characteristics & Low-EATV group & High-EATV group & $P$ value \\
\hline No. of patients & 65 & 65 & \\
\hline Age (years) & $67.7 \pm 10.1$ & $68.0 \pm 9.0$ & 0.83 \\
\hline Height $(\mathrm{cm})$ & $161.6 \pm 9.8$ & $161.1 \pm 9.4$ & 0.78 \\
\hline Body weight (kg) & $62.1 \pm 11.6$ & $61.7 \pm 9.8$ & 0.83 \\
\hline $\operatorname{BMI}\left(\mathrm{kg} / \mathrm{m}^{2}\right)$ & $23.6 \pm 2.9$ & $23.7 \pm 2.8$ & 0.89 \\
\hline Male gender & $53(81.5)$ & $45(69.2)$ & 0.10 \\
\hline \multicolumn{4}{|l|}{ Risk factors } \\
\hline Family history & $24(36.9)$ & $21(32.3)$ & 0.58 \\
\hline Hypertension & $47(72.3)$ & $42(64.6)$ & 0.35 \\
\hline Dyslipidemia & $45(69.2)$ & $41(63.1)$ & 0.46 \\
\hline Current smoker & $18(27.7)$ & $12(18.5)$ & 0.21 \\
\hline Diabetes mellitus & $19(29.2)$ & $24(36.9)$ & 0.35 \\
\hline Total cholesterol (mg/dl) & $181.0 \pm 37.5$ & $186.7 \pm 39.7$ & 0.43 \\
\hline LDL cholesterol (mg/dl) & $99.1 \pm 30.6$ & $105.7 \pm 32.9$ & 0.25 \\
\hline HDL cholesterol (mg/dl) & $48.1 \pm 12.3$ & $46.0 \pm 14.3$ & 0.38 \\
\hline Triglycerides (mg/dl) & $162.5 \pm 110.7$ & $146.6 \pm 100.1$ & 0.41 \\
\hline ApoB/A1 ratio & $0.81 \pm 0.32$ & $0.87 \pm 0.26$ & 0.44 \\
\hline EPA/AA ratio & $0.56 \pm 0.42$ & $0.58 \pm 0.50$ & 0.77 \\
\hline $\mathrm{HbA}_{1 \mathrm{c}}(\mathrm{NGSP})$ & $6.22 \pm 1.01$ & $6.47 \pm 1.25$ & 0.24 \\
\hline $\mathrm{Cr}(\mathrm{mg} / \mathrm{dl})$ & $0.93 \pm 0.16$ & $0.95 \pm 0.18$ & 0.93 \\
\hline Cystatin C (mg/l) & $1.34 \pm 0.24$ & $1.39 \pm 0.26$ & 0.89 \\
\hline hs-CRP (mg/dl) & $0.12 \pm 0.18$ & $0.29 \pm 0.21$ & 0.19 \\
\hline CAC score & $152.3 \pm 86.4$ & $188.6 \pm 92.2$ & 0.17 \\
\hline \multicolumn{4}{|l|}{ Medications } \\
\hline $\mathrm{ARB}$ & $23(35.4)$ & $20(30.8)$ & 0.58 \\
\hline CCB & 29 (44.6) & $34(52.3)$ & 0.38 \\
\hline Statin & $25(38.5)$ & $40(61.5)$ & 0.01 \\
\hline EPA & $6(9.2)$ & $5(7.7)$ & 0.75 \\
\hline
\end{tabular}

\section{Discussion}

The main results obtained by this study were as follows. First, plaque volume was larger at the lesions in the highEATV group, indicating more positive remodeling of lesions in this group. Second, there was a negative correlation between EATV and fibrous plaque while there was a positive correlation between EATV and vulnerable plaque containing lipid and necrotic tissue. Third, LDL cholesterol and EATV were identified as independent factors related to necrotic plaque as a result of multivariate analysis. This was the first study to compare the EATV with plaque characteristics and plaque volume at the lesion identified by iMap-IVUS.

EATV and plaque volume

A relationship between EATV and inflammatory markers has been suggested [16, 17], and EATV was identified as a potential cause of positive remodeling. In the present study, there was no significant difference in MLA between the two groups. Despite the absence of a significant difference between the groups with regard to positive remodeling, the vessel diameter at the lesion tended to be larger in the highEATV group. The plaque at the site of most stenotic lesion is worthy of discussion. It will be necessary in the future to consider plaque in the nonculprit coronary lesion and the distribution of EAT.

EATV and plaque vulnerability

The relation between EATV and plaque vulnerability has been assessed using CT data in several previous studies [35]. IVUS is superior to $\mathrm{CT}$ for characterizing coronary plaque, as described above. In addition, performing iMapIVUS at $40 \mathrm{MHz}$ is a new technique for more objective and reproducible characterization of plaque components at higher resolution [10]. Our study revealed a positive 
Table 2 Comparison of angiographic and CT findings
$M L D$ minimum luminal diameter, $C A C$ coronary artery calcification

\begin{tabular}{|c|c|c|c|}
\hline Angiographic findings & Low-EATV group & High-EATV group & $P$ value \\
\hline Pre MLD (mm) & $1.11 \pm 0.35$ & $1.19 \pm 0.41$ & 0.22 \\
\hline Pre diameter stenosis $(\%)$ & $60.5 \pm 12.5$ & $57.4 \pm 13.6$ & 0.17 \\
\hline Pre reference diameter $(\mathrm{mm})$ & $2.87 \pm 0.71$ & $2.92 \pm 0.73$ & 0.64 \\
\hline Lesion length (mm) & $24.2 \pm 13.4$ & $24.4 \pm 11.4$ & 0.93 \\
\hline Post MLD (mm) & $2.64 \pm 0.60$ & $2.68 \pm 0.69$ & 0.71 \\
\hline Post diameter stenosis $(\%)$ & $12.7 \pm 7.9$ & $13.5 \pm 7.8$ & 0.55 \\
\hline Diseased vessel (\%) & & & 0.83 \\
\hline Left main artery & $1(1.5)$ & $1(1.5)$ & \\
\hline \multicolumn{4}{|l|}{ Left anterior descending artery } \\
\hline Proximal & $18(36.9)$ & $22(49.2)$ & \\
\hline Mid & $5(7.7)$ & $8(12.3)$ & \\
\hline Distal & $1(1.5)$ & $2(3.1)$ & \\
\hline \multicolumn{4}{|l|}{ Left circumflex artery } \\
\hline Proximal & $8(8.1)$ & $4(6.2)$ & \\
\hline Mid & $4(6.2)$ & $4(6.2)$ & \\
\hline Distal & $5(7.7)$ & $4(6.2)$ & \\
\hline \multicolumn{4}{|l|}{ Right coronary artery } \\
\hline Proximal & $7(10.8)$ & $8(12.3)$ & \\
\hline Mid & $7(10.8)$ & $8(12.3)$ & \\
\hline Distal & $9(13.8)$ & $4(6.2)$ & \\
\hline \multicolumn{4}{|l|}{ CT findings } \\
\hline Average no. of plaques & $2.2 \pm 0.6$ & $2.8 \pm 0.8$ & 0.11 \\
\hline No. of stenoses & & & 0.49 \\
\hline $50-75 \%$ & $21(32.3)$ & $17(26.2)$ & \\
\hline More than $75 \%$ & $44(67.7)$ & $48(73.8)$ & \\
\hline Plaque characteristics & & & 0.93 \\
\hline Noncalcified & $40(61.5)$ & $38(58.5)$ & \\
\hline Mixed & $23(35.4)$ & $25(38.5)$ & \\
\hline Calcified & $2(3.1)$ & $2(3.1)$ & \\
\hline CAC score & $64.7 \pm 58.4$ & $98.6 \pm 66.5$ & 0.16 \\
\hline
\end{tabular}

correlation between EATV and components of vulnerable plaque such as necrotic tissue, while there was a negative correlation between EATV and fibrous tissue. Attenuation accompanied by calcified tissue and artifacts from guide wires are sometimes recognized as necrotic tissue when using the iMap system, whereas the QIVUS software defines these as unknown plaque. Because there was only a small difference in calcified tissue between the two groups compared with that of necrotic tissue, the possibility of the study results being influenced by calcified tissue and wire bias can be ruled out.

\section{LDL cholesterol and plaque}

Although the number of patients receiving statin therapy was significantly greater in the high-EATV group, there was no significant difference between low- and high-EATV groups in terms of LDL cholesterol. However, there was a positive correlation between LDL cholesterol and the amount of necrotic tissue on both univariate and multivariate analyses, hence LDL was reaffirmed as the main causal factor of coronary plaque progression. The LDLlowering effect of statins is well known to be efficacious for secondary prevention of cardiovascular events [18], and intensive lipid-lowering therapy with strong statins has been frequently reported to prevent cardiovascular events [19-21]. A prospective randomized trial is necessary to firmly establish how intervention is useful for patients with high EATV.

\section{Limitations}

There were some limitations to this study. First, the sample size was relatively small and this was a singlecenter investigation. Second, only patients who received treatment for coronary artery disease were included in 
Table 3 Comparison of IVUS findings
IVUS intravascular ultrasound, $M L A$ minimum luminal crosssectional area

\begin{tabular}{lccr}
\hline IVUS findings & Low-EATV group & High-EATV group & $P$ value \\
\hline Vessel volume $\left(\mathrm{mm}^{3}\right)$ & $126.6 \pm 44.5$ & $144.6 \pm 53.7$ & 0.04 \\
Luminal volume $\left(\mathrm{mm}^{3}\right)$ & $49.9 \pm 19.3$ & $50.6 \pm 20.2$ & 0.84 \\
Minimum luminal area $\left(\mathrm{mm}^{2}\right)$ & $2.99 \pm 1.14$ & $2.98 \pm 1.01$ & 0.95 \\
Reference area at MLA $\left(\mathrm{mm}^{2}\right)$ & $12.02 \pm 4.46$ & $13.80 \pm 5.38$ & 0.04 \\
Area stenosis at MLA $\left(\mathrm{mm}^{2}\right)$ & $72.9 \pm 10.2$ & $76.5 \pm 8.3$ & 0.03 \\
Lesion length $(\mathrm{mm})$ & $9.9 \pm 0.6$ & $9.9 \pm 0.7$ & 0.55 \\
Remodeling index & $0.87 \pm 0.14$ & $1.04 \pm 0.16$ & 0.07 \\
Plaque volume $\left(\mathrm{mm}^{3}\right)$ & $76.7 \pm 32.2$ & $93.9 \pm 41.6$ & 0.01 \\
Fibrous $\left(\mathrm{mm}^{3}\right)$ & $42.8 \pm 16.4$ & $39.2 \pm 15.5$ & 0.19 \\
Lipid $\left(\mathrm{mm}^{3}\right)$ & $6.0 \pm 3.7$ & $7.9 \pm 4.2$ & 0.01 \\
Necrotic $\left(\mathrm{mm}^{3}\right)$ & $13.6 \pm 8.4$ & $22.8 \pm 12.2$ & $<0.01$ \\
Calcified $\left(\mathrm{mm}^{3}\right)$ & $1.9 \pm 1.3$ & $3.7 \pm 2.3$ & $<0.01$ \\
Unknown $\left(\mathrm{mm}^{3}\right)$ & $7.5 \pm 9.6$ & $14.3 \pm 13.2$ & 0.00 \\
Masked $\left(\mathrm{mm}^{3}\right)$ & $5.22 \pm 4.3$ & $6.6 \pm 4.4$ & 0.07 \\
Fibrous $(\%)$ & $58.6 \pm 14.1$ & $43.4 \pm 11.0$ & $<0.01$ \\
Lipid $(\%)$ & $7.4 \pm 2.4$ & $8.3 \pm 2.3$ & 0.03 \\
Necrotic $(\%)$ & $16.7 \pm 5.7$ & $23.7 \pm 4.8$ & $<0.01$ \\
Calcified $(\%)$ & $2.8 \pm 2.1$ & $4.3 \pm 2.7$ & $<0.01$ \\
\hline
\end{tabular}
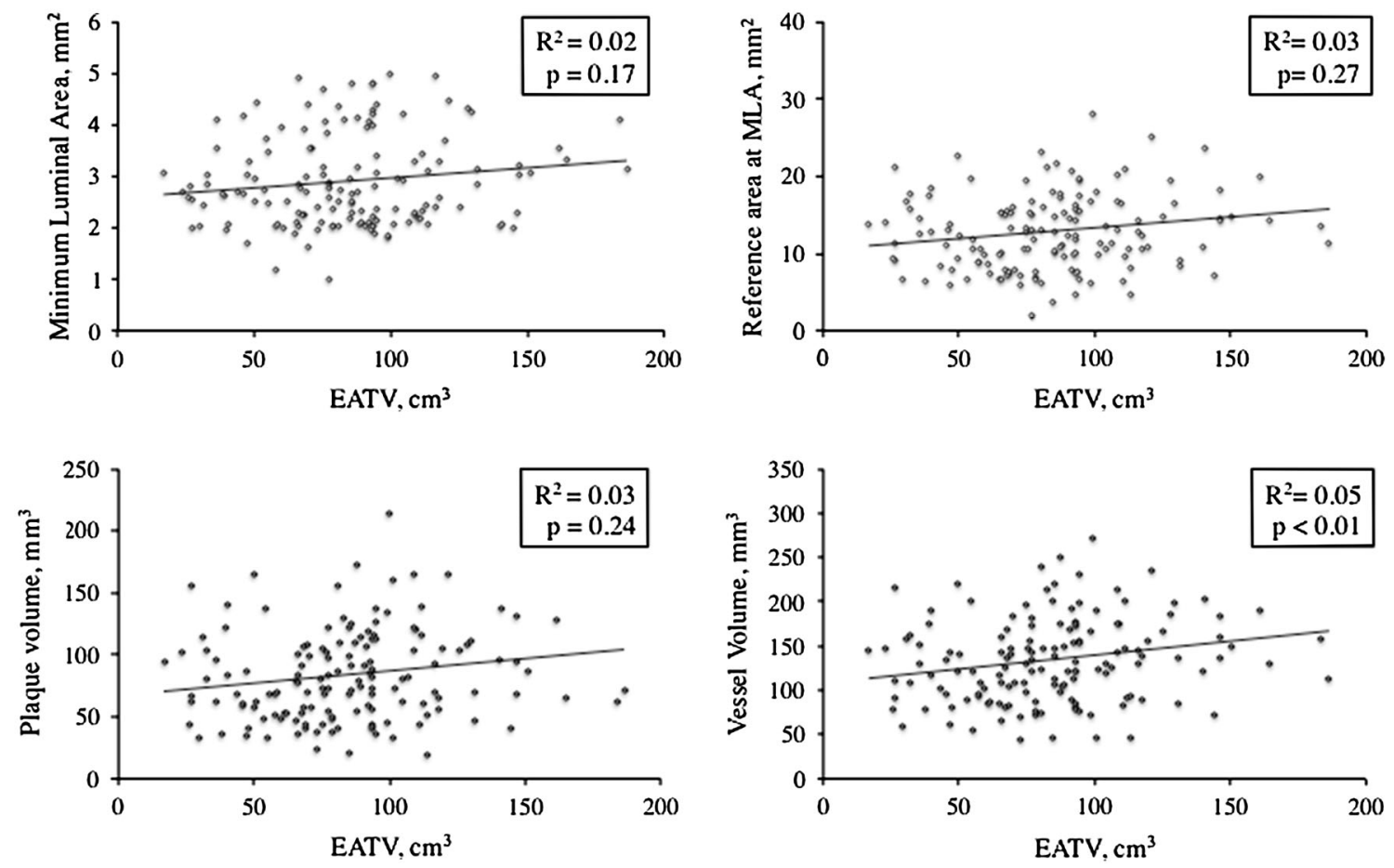

Fig. 4 Relationship of epicardial adipose tissue volume (EATV) with volumetric intravascular ultrasound parameters. $M L A$ minimum luminal cross-sectional area

the study. Moreover, they all had stable angina, while those with acute coronary syndromes were excluded (due to problems with accurate diagnosis of thrombus by IVUS), suggesting a possibility of selection bias. Third, follow-up data were not available and epicardial fat was measured only once. Further investigation will be required in the future to assess changes in EATV and plaque volume. 

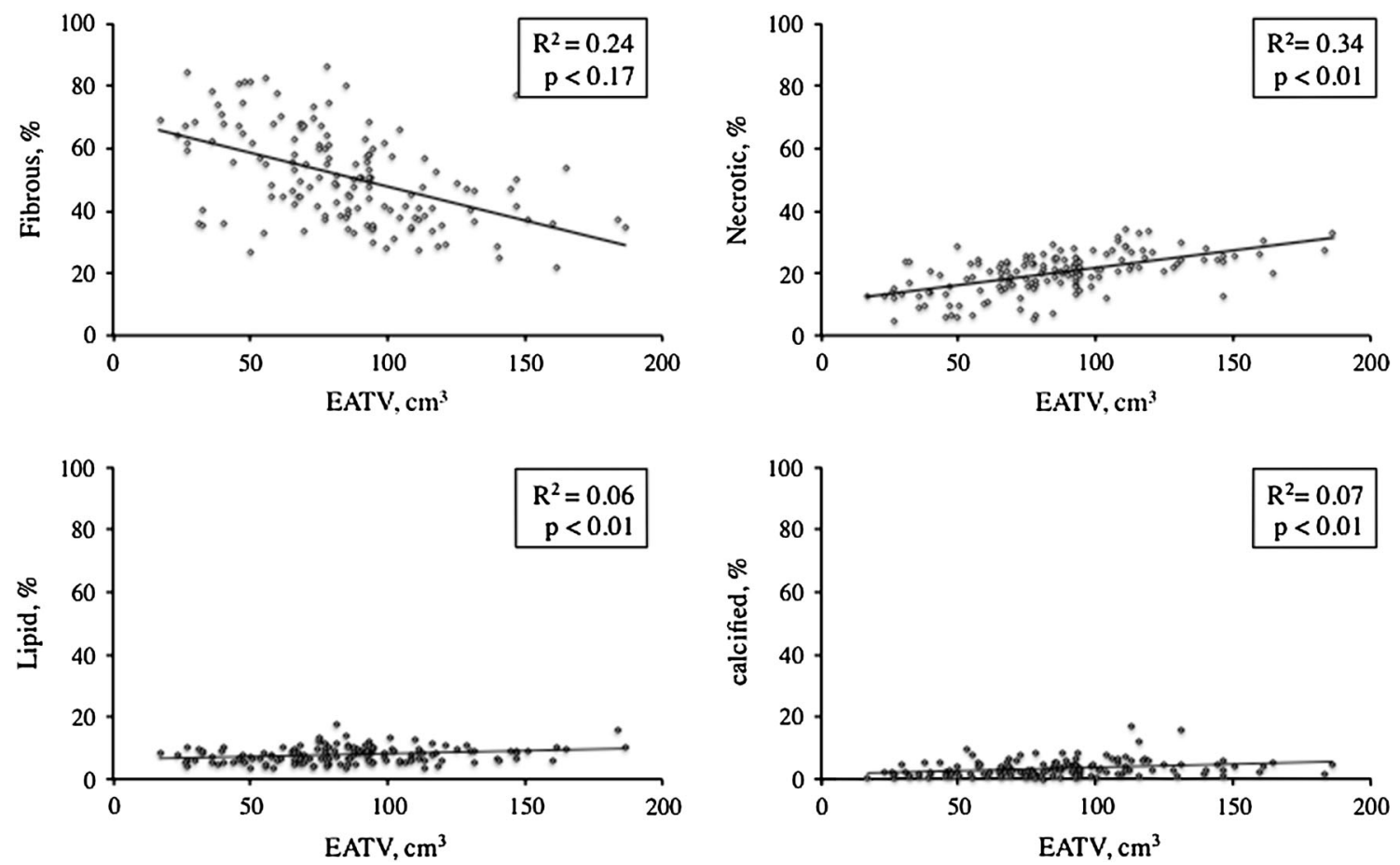

Fig. 5 Relationship of epicardial adipose tissue volume (EATV) with coronary plaque components

Table 4 Multivariate analysis between necrotic tissue on iMap-IVUS and several clinical factors in all patients (A) and in the high-EATV group (B)

\begin{tabular}{|c|c|c|c|c|}
\hline & \multicolumn{2}{|c|}{ Univariate analysis } & \multicolumn{2}{|c|}{ Multivariate analysis } \\
\hline & $R^{2}$ & $P$ & $\beta$ & $P$ \\
\hline \multicolumn{5}{|l|}{ (A) } \\
\hline $\mathrm{HbA}_{1 \mathrm{c}}$ & 0.18 & 0.16 & & \\
\hline LDL cholesterol & 0.38 & $<0.01$ & 0.15 & 0.03 \\
\hline HDL cholesterol & 0.14 & 0.83 & & \\
\hline EPA/AA ratio & 0.08 & 0.39 & & \\
\hline hs-CRP & 0.09 & 0.15 & & \\
\hline EATV & 0.34 & $<0.01$ & 0.14 & 0.02 \\
\hline BMI & 0.10 & 0.43 & & \\
\hline Smoking & 0.16 & 0.55 & & \\
\hline \multicolumn{5}{|l|}{ (B) } \\
\hline $\mathrm{HbA}_{1 \mathrm{c}}$ & 0.16 & 0.61 & & \\
\hline LDL cholesterol & 0.27 & 0.04 & 0.10 & 0.04 \\
\hline HDL cholesterol & 0.06 & 0.12 & & \\
\hline EPA/AA ratio & 0.09 & 0.77 & & \\
\hline hs-CRP & 0.09 & 0.15 & & \\
\hline BMI & 0.18 & 0.43 & & \\
\hline Smoking & 0.03 & 0.22 & & \\
\hline
\end{tabular}

$A A$ arachidonic acid, $B M I$ body mass index, $E P A$ eicosapentaenoic acid, $H b A_{1 c}$ hemoglobin $\mathrm{A}_{1 \mathrm{c}}, H D L$ high-density lipoprotein, $h s-C R P$ highly sensitive C-reactive protein, $L D L$ low-density lipoprotein

\section{Conclusion}

The present study demonstrated that an increase in EATV was associated with the development of coronary atherosclerosis and, potentially, with the most dangerous type of plaque.

Open Access This article is distributed under the terms of the Creative Commons Attribution License which permits any use, distribution, and reproduction in any medium, provided the original author(s) and the source are credited.

\section{References}

1. Ho E, Shimada Y (1978) Formation of the epicardium studied with the scanning electron microscope. Dev Biol 66:579-585

2. Alexopoulos N, McLean DS, Janik M, Arepalli CD, Stillman AE, Raggi P (2010) Epicardial adipose tissue and coronary artery plaque characteristics. Atherosclerosis 210(1):150-154

3. Rosito GA, Massaro JM, Hoffmann U, Ruberg FL, Mahabadi AA, Vasan RS, O'Donnell CJ, Fox CS (2008) Pericardial fat, visceral abdominal fat, cardiovascular disease risk factors, and vascular calcification in a community-based sample: the Framingham Heart Study. Circulation 117(5):605-613

4. Mahabadi AA, Massaro JM, Rosito GA, Levy D, Murabito JM, Wolf PA, O'Donnell CJ, Fox CS, Hoffmann U (2009) Association of pericardial fat, intrathoracic fat, and visceral abdominal fat with cardiovascular disease burden: the Framingham Heart Study. Eur Heart J 30(7):850-856 
5. Tamarappoo B, Dey D, Shmilovich H, Nakazato R, Gransar H, Cheng VY, Friedman JD, Hayes SW, Thomson LE, Slomka PJ, Rozanski A, Berman DS (2010) Increased pericardial fat volume measured from noncontrast CT predicts myocardial ischemia by SPECT. JACC Cardiovasc Imaging 3(11):1104-1112

6. Cheng VY, Dey D, Tamarappoo B, Nakazato R, Gransar H, Miranda-Peats R, Ramesh A, Wong ND, Shaw LJ, Slomka PJ, Berman DS (2010) Pericardial fat burden on ECG-gated noncontrast $\mathrm{CT}$ in asymptomatic patients who subsequently experience adverse cardiovascular events. JACC Cardiovasc Imaging 3(4):352-360

7. Bambace C, Sepe A, Zoico E, Telesca M, Olioso D, Venturi S, Rossi A, Corzato F, Faccioli S, Cominacini L, Santini F, Zamboni M (2013) Inflammatory profile in subcutaneous and epicardial adipose tissue in men with and without diabetes. Heart Vessels. doi:10.1007/s00380-012-0315-9

8. Sakata K, Kawashiri MA, Ino H, Matsubara T, Uno Y, Yasuda T, Miwa K, Kanaya H, Yamagishi M (2011) Intravascular ultrasound appearance of scattered necrotic core as an index for deterioration of coronary flow during intervention in acute coronary syndrome. Heart Vessels 27:443-452

9. Falk E, Shah PK, Fuster V (1995) Coronary plaque disruption. Circulation 92:657-671

10. Sathyanarayana S, Carlier S, Li W, Thomas L (2009) Characterization of atherosclerotic plaque by spectral similarity of radiofrequency intravascular ultrasound signals. EuroIntervention 5(1):133-139

11. Austen WG, Edwards JE, Frye RL, Gensini GG, Gott VL, Griffith LS, McGoon DC, Murphy ML, Roe BB (1975) A reporting system on patients evaluated for coronary artery disease. Report of the Ad Hoc Committee for Grading of Coronary Artery Disease, Council on Cardiovascular Surgery, American Heart Association. Circulation 51:5-40

12. Mintz GS, Nissen SE, Anderson WD, Bailey SR, Erbel R, Fitzgerald PJ, Pinto FJ, Rosenfield K, Siegel RJ, Tuzcu EM, Yock PG (2001) American College of Cardiology Clinical Expert Consensus Document on Standards for Acquisition, Measurement and Reporting of Intravascular Ultrasound Studies (IVUS). A report of the American College of Cardiology Task Force on Clinical Expert Consensus Documents. J Am Coll Cardiol 37(5): 1478-1492

13. Ehara S, Kobayashi Y, Yoshiyama M, Shimada K, Shimada Y, Fukuda D, Nakamura Y, Yamashita H, Yamagishi H, Takeuchi K, Naruko T, Haze K, Becker AE, Yoshikawa J, Ueda M (2004) Spotty calcification typifies the culprit plaque in patients with acute myocardial infarction: an intravascular ultrasound study. Circulation 110(22):3424-3429

14. Agatston AS, Janowitz WR, Hildner FJ, Zusmer NR, Viamonte M Jr, Detrano R (1990) Quantification of coronary artery calcium using ultrafast computed tomography. J Am Coll Cardiol 15(4):827-832

15. Wheeler GL, Shi R, Beck SR, Langefeld CD, Lenchik L, Wagenknecht LE, Freedman BI, Rich SS, Bowden DW, Chen MY, Carr JJ (2005) Pericardial and visceral adipose tissues measured volumetrically with computed tomography are highly associated in type 2 diabetic families. Invest Radiol 40(2):97-101

16. Mazurek T, Zhang L, Zalewski A, Mannion JD, Diehl JT, Arafat H, Sarov-Blat L, O'Brien S, Keiper EA, Johnson AG, Martin J, Goldstein BJ, Shi Y (2003) Human epicardial adipose tissue is a source of inflammatory mediators. Circulation 108(20):2460-2466

17. Baker AR, Silva NF, Quinn DW, Harte AL, Pagano D, Bonser RS, Kumar S, McTernan PG (2006) Human epicardial adipose tissue expresses a pathogenic profile of adipocytokines in patients with cardiovascular disease. Cardiovasc Diabetol 5:1

18. National Cholesterol Education Program (NCEP) Expert Panel on Detection, Evaluation, and Treatment of High Blood Cholesterol in Adults (Adult Treatment Panel III) (2012) Third Report of the National Cholesterol Education Program (NCEP) Expert Panel on Detection, Evaluation, and Treatment of High Blood Cholesterol in Adults (Adult Treatment Panel III) final report. Circulation 106(25):3143-3421

19. Grundy SM, Cleeman JI, Merz CN, Brewer HB Jr, Clark LT, Hunninghake DB, Pasternak RC, Smith SC Jr, Stone NJ (2012) National Heart, Lung, and Blood Institute; American College of Cardiology Foundation; American Heart Association. Implications of recent clinical trials for the National Cholesterol Education Program Adult Treatment Panel III guidelines. Circulation 110(2):227-239

20. LaRosa JC, Grundy SM, Waters DD, Shear C, Barter P, Fruchart JC, Gotto AM, Greten H, Kastelein JJ, Shepherd J, Wenger NK, Treating to New Targets (TNT) Investigators (2005) Intensive lipid lowering with atorvastatin in patients with stable coronary disease. N Engl J Med 352(14):1425-1435

21. Gibson CM, Pride YB, Hochberg CP, Sloan S, Sabatine MS, Cannon CP (2009) TIMI Study Group. Effect of intensive statin therapy on clinical outcomes among patients undergoing percutaneous coronary intervention for acute coronary syndrome. PCIPROVE IT: a PROVE IT-TIMI 22 (Pravastatin or Atorvastatin Evaluation and Infection Therapy-Thrombolysis In Myocardial Infarction 22) substudy. J Am Coll Cardiol 54(24):2290-2295 